\title{
The Importance of Education in Laser Doppler Imaging Diagnostics
}

S. Taheri Bandari, RN, A. Kaartinen, RN, S. Kalliomäki, RN, H. Siivonen, NM, S. Ilmarinen, NM. J.Vuola, MD,PhD. Helsinki Burn Centre, Finland

\section{Introduction}

Laser Doppler Imaging (LDi) has been used in burn depth evaluation since 1993. The purpose of this work is to demonstrate the importance of valid Laser Doppler education to obtain proper burn depth assessment.

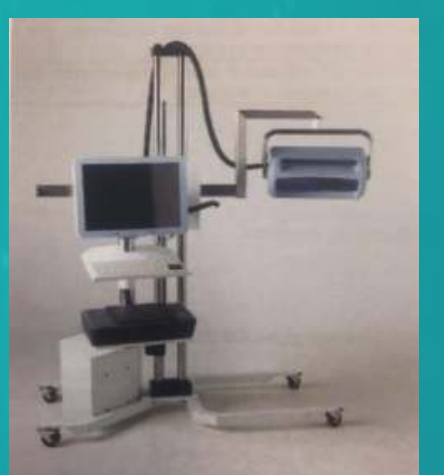

\section{The LD interpret flow colours:}

Red coulour $=$ Healing potential in 14 days

Yellow colour $=$ Healing potential between 14 and 21 days

Blue colour $=$ Healing potential $>21$, no healing by day 21

\section{Results}

The presented patient cases illustrated, that performing LDi imaging without proper training gives false results. Scientific studies and practice confirm the result of the patient case.

The patient had mainly superficial injuries in the front of the body, which were healed by conservative treatment in 21 days. Both arms and shoulders, both hands and the right upper arm had deep injuries that required excision. Both legs had partially deep burns and deep burns that required also revision and excision.

\section{Conclusion}

In the evaluation of the depth of a burn, LD imaging is a useful tool for the patient treatment when performed by a nurse who has received valid device training.

\section{Methods}

The interfering factors affecting the quality of LD imaging and interpretation and reliability of results were identified through literature review and in practice. In the patient case with two separate imaging sessions were performed.

In the first imaging, manufacturer's instructions were followed exactly and recommendations from the literature review were taken into consideration when performing LD imaging.
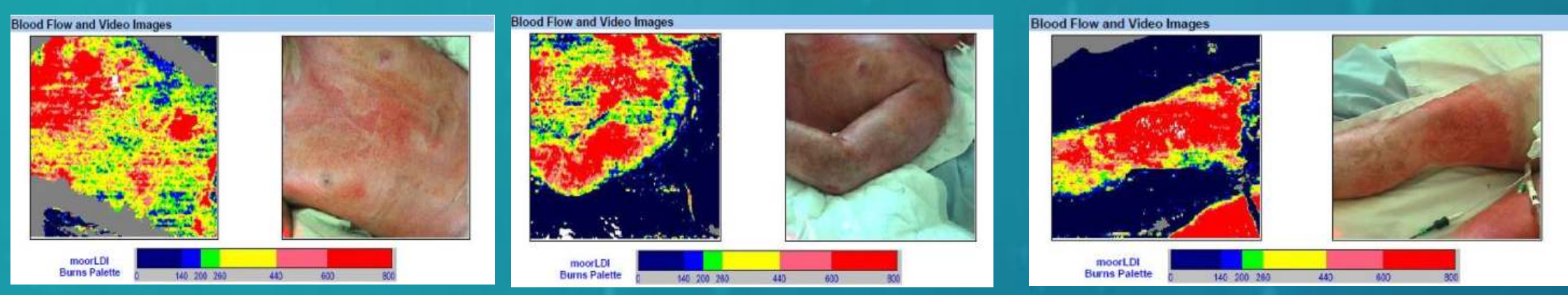

In the second imaging below, we did not take the disturbance factors into account. The blisters and dead skin remnants were not removed before LD imaging. We ignored the oxygen mask tube, indwelling catheter tube and invasive tubes. We also added instrument next to the patient and pillow on the chest where the burns were. Then we compared the two different methods.

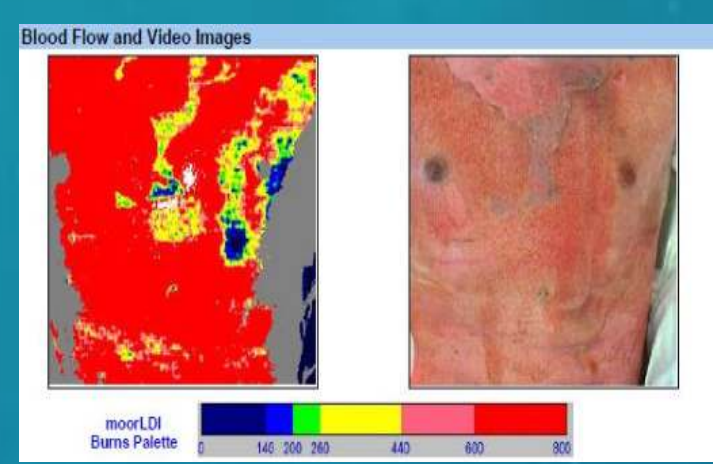

Dead tissue was not removed, the result is incorrectly superficial burn.

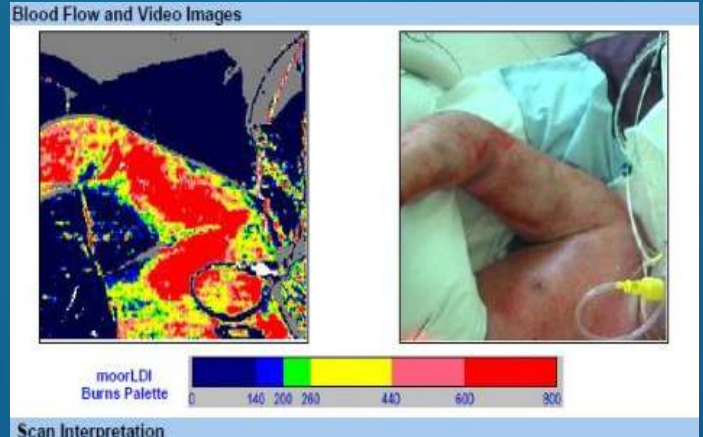

The oxygen mask tube and invasive tubes were added to LD imagine. The result was incorrectly a deep burn.

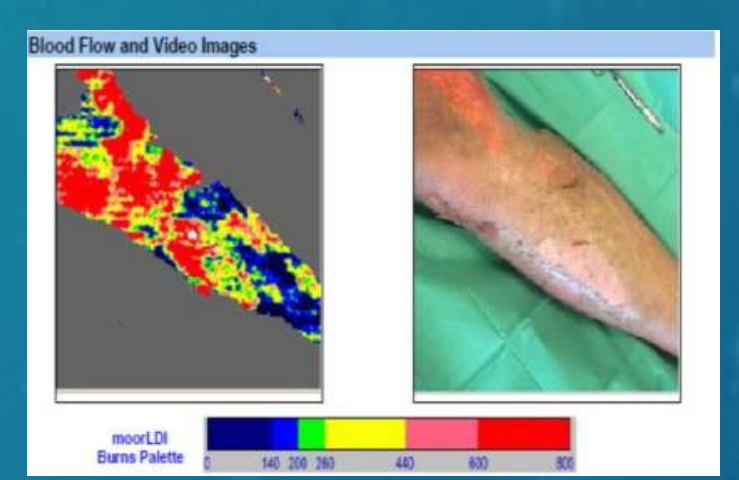

Dead tissue from the right leg was not removed, the result is incorrectly mainly deeper burns. The scissors were also added to LD imagine showing incorrectly skin blood flow.
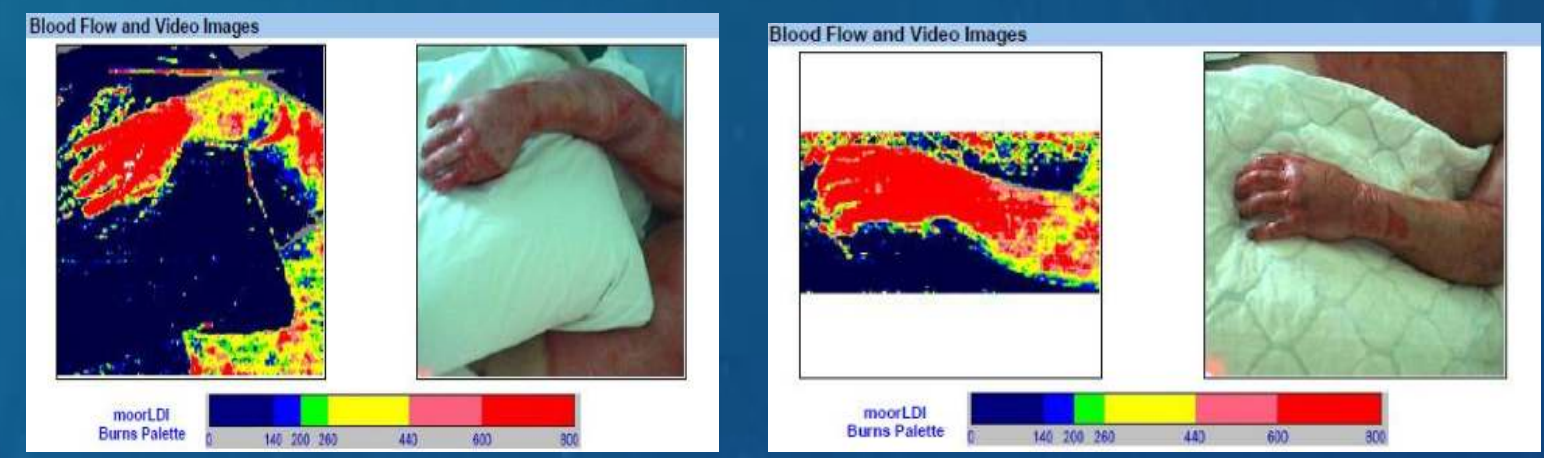

The pillow on the body give the incorrectly results, deep burn.

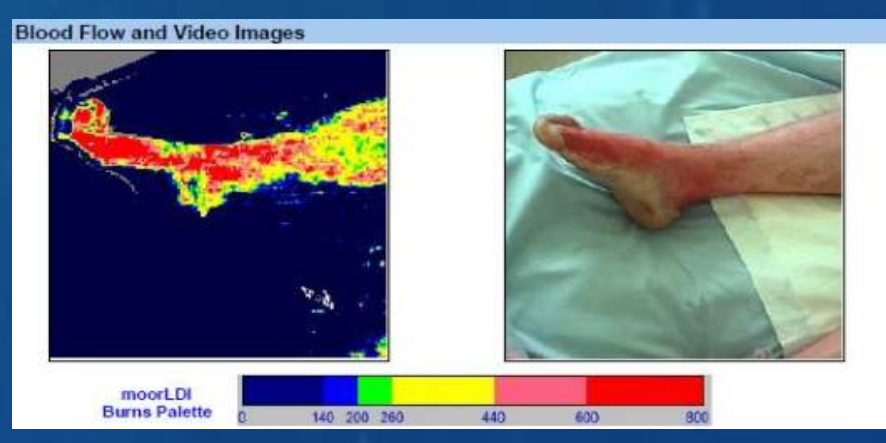

The sole has healthy skin, depicted in deep blue colour. On the other hand, deep burn has the same colour, which has to be taken into account.
Indwelling catheter tube gave the incorrect result, deep burn.
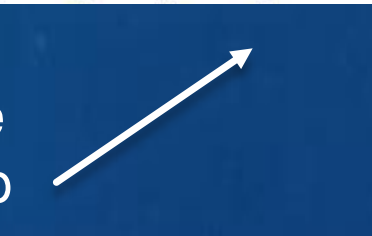

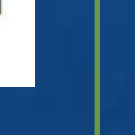

\section{Sources:}

1: Pape SA et al. Burn wound healing time assessed by laser Doppler imaging (LDI). Part 1: Derivation of a dedicated colour code for image interpretation. Burns. 2012 Mar;38(2):187-94.

2: Monstrey SM et al. Burn wound healing time assessed by laser Doppler imaging. Part 2: validation of a dedicated colour code for image interpretation. Burns. 2011 Mar;37(2):249-56.

3: Hop MJ et al. Cost-Effectiveness of Laser Doppler Imaging in Burn Care in The Netherlands: A Randomized Controlled Trial. Plast Reconstr Surg. 2016 Jan;137(1):166e-176e.

4: Monstrey S et al. Assessment of burn depth and burn wound healing potential. Burns. 2008 Sep;34(6):761-9. 5: MoorLDI2-BI System User Manual,v. 3.0, Iss 3

Revision Date: 25/07/2012 